\title{
Spontaneous Vesicle Formation in Catanionic Mixtures of Amino Acid-Based Surfactants: Chain Length Symmetry Effects
}

\author{
Eduardo F. Marques, ${ }^{*}{ }^{\dagger}$ Rodrigo O. Brito, ${ }^{\dagger}$ Sandra G. Silva, ${ }^{\dagger}$ J. Enrique Rodríguez-Borges, \\ Maria Luísa do Vale, ${ }^{\dagger}$ Paula Gomes, ${ }^{\dagger}$ Maria J. Araújo ${ }^{\dagger}{ }^{\dagger}$ and Olle Söderman ${ }^{\ddagger}$ \\ Centro de Investigação em Química, Department of Chemistry, Faculty of Science, University of Porto, \\ Rua do Campo Alegre, no. 687, P 4169-007 Porto, Portugal, and Physical Chemistry 1, Centre for \\ Chemistry and Chemical Engineering, Lund University, P.O. Box 124, SE-22100 Lund, Sweden
}

Received May 17, 2008. Revised Manuscript Received June 29, 2008

\begin{abstract}
The use of amino acids for the synthesis of novel surfactants with vesicle-forming properties potentially enhances the biocompatibility levels needed for a viable alternative to conventional lipid vesicles. In this work, the formation and characterization of catanionic vesicles by newly synthesized lysine- and serine-derived surfactants have been investigated by means of phase behavior mapping and PFG-NMR diffusometry and cryo-TEM methods. The lysinederived surfactants are double-chained anionic molecules bearing a pseudogemini configuration, whereas the serinederived amphiphile is cationic and single-chained. Vesicles form in the cationic-rich side for narrow mixing ratios of the two amphiphiles. Two pairs of systems were studied: one symmetric with equal chain lengths, $2 \mathrm{C}_{12} / \mathrm{C}_{12}$, and the other highly asymmetric with $2 \mathrm{C}_{8} / \mathrm{C}_{16}$ chains, where the serine-based surfactant has the longest chain. Different mechanisms of the vesicle-to-micelle transition were found, depending on symmetry: the $2 \mathrm{C}_{12} / \mathrm{C}_{12}$ system entails limited micellar growth and intermediate phase separation, whereas the $2 C_{8} / C_{16}$ system shows a continuous transition involving large wormlike micelles. The results are interpreted on the basis of currently available models for the micelle-vesicle transitions and the stabilization of catanionic vesicles (energy of curvature vs mixing entropy).
\end{abstract}

\section{Introduction}

Catanionic vesicles, which are formed upon the mixing of two oppositely charged surfactants in solution, have been subject to extensive experimental ${ }^{1-10}$ and theoretical ${ }^{11-14}$ investigations, mostly as as result of their long-term stability and spontaneous formation from the neat micellar solutions. The versatile physicochemical properties of these vesicles, namely, regulation of charge, size, and volume fraction in solution, have allowed for several application-related studies, such as the preparation of magnetic nanoparticles ${ }^{15}$ and hollow spheres ${ }^{16-19}$ and the

* Corresponding author. E-mail: efmarque@fc.up.pt.

${ }^{\dagger}$ University of Porto.

* Lund University.

(1) Kaler, E. W.; Murthy, A. K.; Rodriguez, B. E.; Zasadzinski, J. A. N. Science 1989, 245, 1371-1374.

(2) Kaler, E. W.; Herrington, K. L.; Murthy, A. K.; Zasadzinski, J. A. N. J. Phys. Chem. 1992, 96, 6698-6707.

(3) Marques, E. F.; Regev, O.; Khan, A.; Miguel, M. d. G.; Lindman, B. $J$. Phys. Chem. B 1998, 102, 6746-6758.

(4) Marques, E. F.; Regev, O.; Khan, A.; Miguel, M. d. G.; Lindman, B. J. Phys. Chem. B 1999, 103, 8353-8363.

(5) Zemb, T.; Dubois, M.; Deme, B.; Gulik-Krzywicki, T. Science 1999, 283, 816-819.

(6) Marques, E. F.; Regev, O.; Khan, A.; Lindman, B. Adv. Colloid Interface Sci. 2003, 100-102, 83-104.

(7) Tondre, C.; Caillet, C. Adv. Colloid Interface Sci. 2001, 93, 115-134.

(8) Antonietti, M.; Förster, S. Adv. Mater. 2003, 15, 1323-1333.

(9) Gradzielski, M. J. Phys.: Condens. Matter 2003, 15, R655-R697.

(10) Segota, S.; Tezak, D. u.-i. Adv. Colloid Interface Sci. 2006, 121, 51-75.

(11) Szleifer, I.; Kramer, D.; Ben-Shaul, A.; Roux, D.; Gelbart, W. M. Phys. Rev. Lett. 1988, 60, 1966-1969.

(12) Safran, S. A.; Pincus, P.; Andelman, D. Science 1990, 248, 354-356.

(13) Yuet, P. K.; Blankschtein, D. Langmuir 1996, 12, 3802-3818.

(14) Jung, H. T.; Coldren, B.; Zasadzinski, J. A.; Iampietro, D. J.; Kaler, E. W. Proc. Natl. Acad. Sci. U.S.A. 2001, 98, 1353-1357.

(15) Yaacob, I. I.; Nunes, A. C.; Bose, A. J. Colloid Interface Sci. 1995, 171, 73-84.

(16) Hentze, H. P.; Raghavan, S. R.; McKelvey, C. A.; Kaler, E. W. Langmuir 2003, 19, 1069-1074.

(17) McKelvey, C. A.; Kaler, E. W.; Zasadzinski, J. A.; Coldren, B.; Jung, H. T. Langmuir 2000, 16, 8285-8290.

(18) Kepczynski, M.; Lewandowska, J.; Romek, M.; Zapotoczny, S.; Ganachaud, F.; Nowakowska, M. Langmuir 2007, 23, 7314-7320. formation of polymer-vesicle gels and networks. ${ }^{20,21}$ Furthermore, because of their solute-entrapment ability, they have been used in the encapsulation of probe molecules ${ }^{22,23}$ and pharmaceutical drugs. ${ }^{24}$ DNA compaction/decompaction and encapsulation studies, envisioning gene delivery applications, ${ }^{25,26}$ have also been carried out.

Hence, catanionic vesicles presently stand as a serious conceptual alternative to the classical lipid-based vesicles, where complex preparation protocols as well as chemical and longterm colloidal stability may cause serious drawbacks. ${ }^{27,28}$ However, lipids are usually well tolerated by living organisms, and toxicity does not pose a problem for in vivo applications, in contrast to some common synthetic amphiphiles. The use of amino acid molecules for the synthesis of surfactants is one possible way to achieve the reduced toxicity decrease and enhanced biocompatibility ${ }^{29-31}$ needed for in vivo applications. Recently, the preliminary assessment of the biological properties

(19) Pevzner, S.; Regev, O.; Lind, A.; Linden, M. J. Am. Chem. Soc. 2003, $125,652-653$.

(20) Antunes, F. E.; Brito, R. O.; Marques, E. F.; Lindman, B.; Miguel, M. J. Phys. Chem. B 2007, 111, 116-123.

(21) Marques, E. F.; Regev, O.; Khan, A.; Miguel, M. G.; Lindman, B. Macromolecules 1999, 32, 6626-6637.

(22) Caillet, C.; Hebrant, M.; Tondre, C. Langmuir 2000, 16, 9099-9102.

(23) Fischer, A.; Hebrant, M.; Tondre, C. J. Colloid Interface Sci. 2002, 248, $163-168$.

(24) Danoff, E. J.; Wang, X.; Tung, S. H.; Sinkov, N. A.; Kemme, A. M.; Raghavan, S. R.; English, D. S. Langmuir 2007, 23, 8965-8971.

(25) Dias, R. S.; Lindman, B.; Miguel, M. G. J. Phys. Chem. B 2002, 106, $12600-12607$.

(26) Rosa, M.; Miguel, M. d. G.; Lindman, B. J. Colloid Interface Sci. 2007, 312, 87-97.

(27) Laughlin, R. G. Colloids Surf., A 1997, 128, 27-38.

(28) Lasic, D. D.; Joannic, R.; Keller, B. C.; Frederik, P. M.; Auvray, L. Adv. Colloid Interface Sci. 2001, 89-90, 337-349.

(29) Vives, M. A.; Macian, M.; Seguer, J.; Infante, M. R.; Vinardell, M. P. Toxicol. in Vitro 1997, 11, 779-783.

(30) Infante, M. R.; Perez, L.; Pinazo, A.; Clapes, P.; Moran, M. C.; Angelet, M.; Garcia, M. T.; Vinardell, M. P. C. R. Chim. 2004, 7, 583-592.

(31) Brito, R. O.; Marques, E. F.; Silva, S. G.; Vale, M. L. d.; Gomes, P.; Araújo, M. J.; Rodriguez-Borges, J. E.; Infante, M. R.; Garcia, M. T.; Ribosa, I.; Vinardell, M. P.; Mitjans, M. Submitted for publication, 2008. 


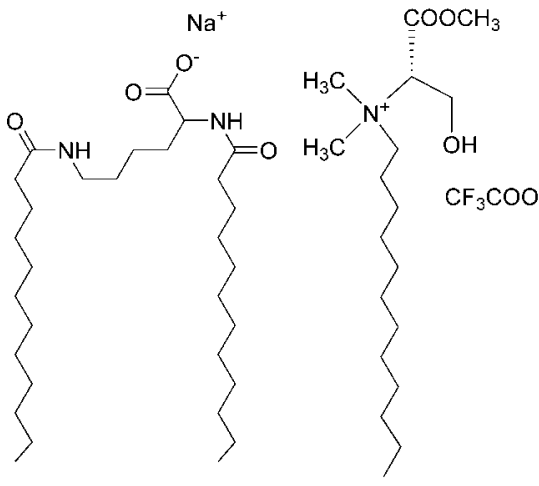

(a)

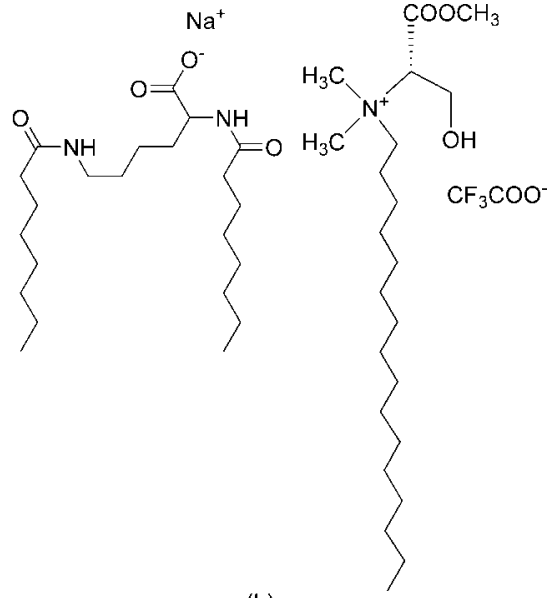

(b)

Figure 1. Molecular structure of the lysine- and serine-based surfactants used for the formation of catanionic mixtures: (a) symmetric 12Lys12/12Ser pair and (b) asymmetric 8Lys8/16Ser pair.

of catanionic mixtures containing amino acid-derived surfactants showed very positive results, ${ }^{31}$ with respect to aquatic toxicity, using the Daphnia magna acute immobilization test, ${ }^{32}$ and hemolytic activity, using a validated red blood cell (RBC) test. ${ }^{33}$ It is shown that the catanionic association into vesicles leads to even lower toxicity levels as compared with that of the individual amino acid-based surfactants, which per se are already slight or moderate irritants. ${ }^{31}$

Another common use of vesicles is in biomembrane modeling, ${ }^{34}$ where peptides and proteins extracted from cells can be reconstituted and incorporated into the bilayers, maintaining their functionality and native conformation. ${ }^{35,36}$ The most common protein extraction process involves cell membrane solubilization by a detergent, which is typically a micellizing surfactant. ${ }^{37,38}$ For the assembly of the peptides on the bilayer, stable vesicles must be formed from the micellar solution. Control of the stability and dynamics of the mixed vesicles is a crucial condition; therefore, a good knowledge of the micelle-vesicle transition process upon changes in composition is also directly relevant.

The disruption of bilayers by micellizing surfactant starts with the insertion of the latter into the bilayer until it becomes saturated and unstable as a result of the composition change. Mixed micelles rich in the micellizing surfactant then form. The transition between vesicles and mixed micelles can typically occur via two paths: ${ }^{35-37}$ a direct, continuous process where micelles form directly from vesicles or a discontinuous transition with a phaseseparation region between the micellar and vesicular phases.

In this work, we investigate the aggregation properties of two catanionic mixtures based on synthetic lysine- and serine-derived surfactants with different chain lengths (Figure 1). The mixed systems were primarily chosen for their ability to yield spontaneously formed vesicles, which remain stable over time. By also focusing on systems sufficiently dissimilar in terms of chain length matching, one could allow for marked differences

(32) OECD, OECD Guidelines for the Testing of Chemicals, 2004.

(33) Pape, W. J.; Pfannenbecker, U.; Hoppe, U. Mol. Tox. 1987, 1, 525-536.

(34) Blume, A.; Gabriel, P., Lipid model membranes and biomembranes. In Handbook of Thermal Analysis and Calorimetry; Kemp, R. B., Ed.; Elsevier: Amsterdam, 1999.

(35) Wagner, A.; Stiegler, G.; Vorauer-Uhl, K.; Katinger, H.; Quendler, H.; Hinz, A.; Weissenhorn, W. J. Liposome Res. 2007, 17, 139-154.

(36) Lu, R.-C.; Xiao, J.-X.; Cao, A.-N.; Lai, L.-H.; Zhu, B.-Y.; Zhao, G.-X. Biochim. Biophys. Acta 2005, 1722, 271-281.

(37) Seddon, A. M.; Curnow, P.; Booth, P. J. Biochim. Biophys. Acta 2004, 1666, 105-117.

(38) Koynova, R.; Tenchov, B. Curr. Opin. Colloid Interface Sci. 2001, 6, 277-286. to occur in aggregation behavior. Thus, one mixture involves molecules with equal hydrocarbon chain lengths $\left(2 \mathrm{C}_{12} / \mathrm{C}_{12}\right.$ pair $)$ and is termed herein the symmetric system; the other has molecules with pronounced differences in chain length $\left(2 \mathrm{C}_{8} / \mathrm{C}_{16}\right.$ pair) and is referred to as the asymmetric system (Figure 1). A comparative analysis of chain length effects both on the vesicle-micelle transition and on the structure/stability of the vesicles can be carried out. These comparisons become even

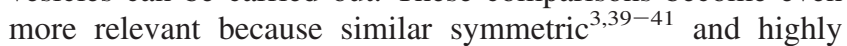
asymmetric mixtures ${ }^{42,43}$ (namely $\mathrm{C}_{8} / \mathrm{C}_{16}$ ) of the catanionic type have been previously investigated and involved commercially available surfactants, so general trends can be tentatively obtained. The results are critically evaluated and discussed on the basis of current models for vesicle stabilization and the micellevesicle transition in mixed surfactant systems, which seem to fit well with the main observations.

\section{Experimental Section}

2.1. Materials. The lysine derivatives, sodium $N, N$-dioctanoylL-lysinate (8Lys8) and sodium N,N-didodecanoyl-L-lysinate (12Lys12), were synthesized as previously published. ${ }^{39,44}$ The serine derivatives, $\mathrm{N}$-dodecyl- $\mathrm{N}, \mathrm{N}$-dimethyl- $\mathrm{N}$-(1-methyloxycarbonil-2-hydroxyethyl) ammonium trifluoroacetate (12Ser) and $N$-hexadecyl- $N, N$ dimethyl- $N$-(1-methyloxycarbonil-2-hydroxyethyl) ammonium trifluoroacetate (16Ser), were synthesized as published elsewhere. ${ }^{45}$ Extensive purity characterization of the compounds is published together with the synthesis details.

2.2. Sample Preparation. Samples for the mapping of phase behavior were prepared by mixing individual surfactant micellar solutions, followed by thorough homogenization. Typically, prior to observations and measurements, the samples were allowed to rest at least $24 \mathrm{~h}$ at the desired fixed temperature. For the 12Lys12/12Ser system, all of the formed $12 \mathrm{Ser}$-rich solutions remain stable at 25 ${ }^{\circ} \mathrm{C}$, a value well above the Krafft temperature $\left(T_{\mathrm{Kr}}\right)$ of $12 \mathrm{Ser}$, and thus this was chosen as the working temperature. For the 8Lys8/

(39) Brito, R. O.; Marques, E. F.; Gomes, P.; Falcão, S.; Söderman, O. J. Phys. Chem. B 2006, 110, 18158-18165.

(40) Herrington, K. L.; Kaler, E. W.; Miller, D. D.; Zasadzinski, J. A.; Chiruvolu, S. J. Phys. Chem. 1993, 97, 13792-13802.

(41) Söderman, O.; Herrington, K. L.; Kaler, E. W.; Miller, D. D. Langmuir 1997, 13, 5531-5538.

(42) Silvander, M.; Karlsson, G.; Edwards, K. J. Colloid Interface Sci. 1996, 179, 104-113.

(43) Yatcilla, M. T.; Herrington, K. L.; Brasher, L. L.; Kaler, E. W.; Chiruvolu, S.; Zasadzinski, J. A. J. Phys. Chem. 1996, 100, 5874-5879.

(44) Gomes, P.; Araújo, M. J.; Marques, E. F.; Falcão, S.; Brito, R. O. Synth. Commun. 2008, 38.

(45) Silva, S.; Borges, J. E.; Marques, E. F.; Vale, M. L. Submitted for publication, 2008. 
16Ser system, since $16 \operatorname{Ser}$ has $T_{\mathrm{Kr}} \approx 33-34^{\circ} \mathrm{C}$ the chosen temperature was set to $35^{\circ} \mathrm{C}$ to avoid the formation of $16 \mathrm{Ser}$ crystals. Significant peak broadening observed in the ${ }^{1} \mathrm{H}$ NMR spectra of mixed 8Lys8/ 16Ser solutions (indicating much slower alkyl chain motions) below ca. $33-34{ }^{\circ} \mathrm{C}$ also gave further justification for the use of $35^{\circ} \mathrm{C}$. High-quality Millipore water was used as the solvent for the phasemapping samples. Samples used for NMR and cryo-TEM studies were prepared by the same procedure but with deuterated water (from Armar Chemicals, Switzerland) as the solvent, showing no change in phase behavior. Here, the total surfactant concentration was kept constant and equal to $0.5 \mathrm{wt} \%$. The mixture composition is expressed both in surfactant weight percentage (useful for phase maps) and in terms of the molar fraction of the Ser-derived surfactant, with respect to the total surfactant amount, according to $X_{\text {Ser }}=$ $n_{\text {Ser }} /\left(n_{\text {Ser }}+n_{\text {Lys }}\right)$, to allow for discussions on a more molecular basis.

2.3. Surface Tension. A DCAT11 surface tensiometer from Dataphysics Instruments $\mathrm{GmbH}$ was used. Measurements were made using a Wilhelmy plate, and data acquisition was done using the software provided by the manufacturer. Temperature was kept constant using a thermostatted Julabo F20 circulating water bath $\left( \pm 0.2^{\circ} \mathrm{C}\right)$ and was set to $25.0^{\circ} \mathrm{C}$ for $8 \mathrm{Lys} 8$ and $12 \mathrm{Ser}$. For $16 \mathrm{Ser}$ and 12Lys12, the temperatures used were 35.0 and $43.0{ }^{\circ} \mathrm{C}$, respectively, 1 to $2{ }^{\circ} \mathrm{C}$ above the $T_{\mathrm{Kr}}$ of each surfactant.

2.4. Polarized Light Microscopy (PLM). PLM imaging of the samples was done using an Olympus BX51 polarized light microscope equipped with differential interference contrast (DIC) at the appropriate temperature as controlled by a Linkam hot stage TH600 plate. The images were acquired with an Olympus DP71 digital camera and processed using the cellA software from the manufacturer.

2.5. Pulsed Field Gradient NMR (PFG NMR) Diffusometry. PFG NMR experiments for molecular diffusometry were carried out with a $200 \mathrm{MHz}$ Bruker DMX200 spectrometer with a gradient coil capable of generating a maximum gradient of $9.4 \mathrm{~T} \mathrm{~m}^{-1}$. The $\mathrm{rf}$ pulse sequence used to measure the water self-diffusion was the Hahn spin-echo sequence, whereas for the monitoring of surfactant self-diffusion, owing to the large $T_{1}$ effect, the stimulated echo sequence was used. ${ }^{46,47}$ Samples were kept in a thermostatted water bath (25.0 or $35.0{ }^{\circ} \mathrm{C}$, see above) before being transferred to the spectrometer and equilibrated at least for $10 \mathrm{~min}$ at the same temperature prior to measurements.

2.6. Cryogenic Transmission Electron Microscopy (CryoTEM). Cryo-TEM imaging was done to assess the formed microstructures and confirm the calculation of aggregate size. The visualized samples were blotted on a copper grid and quickly vitrified in liquid ethane from the desired temperature. ${ }^{48,49}$ Following the vitrification step, samples were transferred in liquid nitrogen to a Philips CM 120 Bio-Twin transmission electron microscope for imaging.

\section{Results}

\subsection{Phase Behavior for the Dilute Catanionic Mixtures.} The critical micellar concentrations $(\mathrm{cmc})$, the surface tension at the critical micellar concentration $\left(\gamma_{\mathrm{cmc}}\right)$, the surface excess $(\Gamma)$, and the surface area per molecule $\left(A_{\mathrm{m}}\right)$ were initially determined for the neat surfactants by means of surface tension. The variation of the surface tension with the logarithm of the surfactant concentration is plotted in Figure 2. The cmc value is determined from the inflection point in the curves. The surface excess $(\Gamma)$ was determined using the Gibbs adsorption equation:

$$
\Gamma=-\frac{1}{2.303 n \mathrm{R} T}\left(\frac{\partial \gamma}{\partial \log c}\right)_{T}
$$

The surface area per molecule $\left(A_{\mathrm{m}}\right)$ is given by

$$
A_{\mathrm{m}}=\left(N_{\mathrm{A}} \Gamma\right)^{-1}
$$

where $R$ is the ideal gas constant, $N_{\mathrm{A}}$ is Avogadro's number, $T$ is the absolute temperature, $(\partial \gamma / \partial \log c)$ is the slope of the surface tension $-\log c$ plot below the $\mathrm{cmc}$, and $n$ corresponds to the

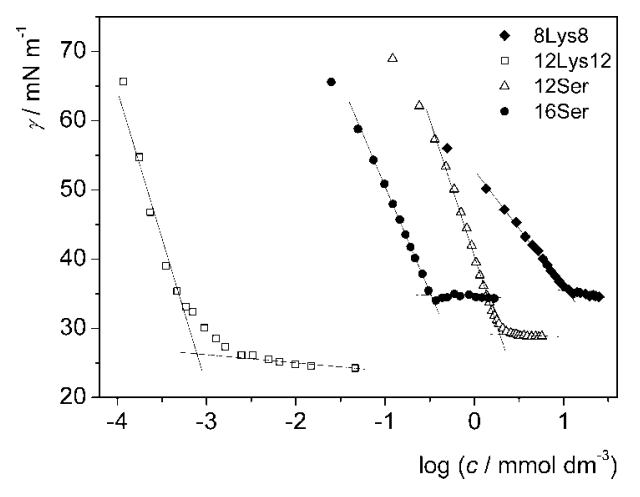

Figure 2. Surface tension vs log concentration (c) curves for the different surfactants. The cmc is determined from the intersection point of the straight lines.

Table 1. Surface Tension at the Critical Micellar Concentration $\left(\gamma_{\mathrm{cmc}}\right)$, Critical Micellar Concentration $(\mathrm{cmc})$, Surface Excess $(\Gamma)$, and Surface Area Per Molecule $\left(A_{\mathrm{m}}\right)$ for the Studied Surfactants

\begin{tabular}{lcclcc}
\hline surfactant & $T\left({ }^{\circ} \mathrm{C}\right)$ & $\begin{array}{c}\gamma_{\mathrm{cmc}} \\
\left(\mathrm{mN} \mathrm{m}^{-1}\right)\end{array}$ & $\begin{array}{c}\mathrm{cmc} \\
\left(\mathrm{mmol} \mathrm{dm}^{-3}\right)\end{array}$ & $\begin{array}{c}10^{6} \Gamma \\
\left(\mathrm{mol} \mathrm{m}^{-2}\right)\end{array}$ & $\begin{array}{c}A_{\mathrm{m}} \\
\left(\mathrm{nm}^{2}\right)\end{array}$ \\
\hline 8Lys8 & 25.0 & 35.3 & 11.2 & 1.4 & 1.1 \\
12Lys12 & 43.0 & 27.1 & $0.55 \times 10^{-3}$ & 9.3 & 0.18 \\
12Ser & 25.0 & 29.2 & 1.9 & 3.6 & 0.46 \\
16Ser & 35.0 & 34.7 & 0.33 & 2.5 & 0.66
\end{tabular}

number of species at the interface. In the case of $8 \mathrm{Lys} 8,12 \mathrm{Ser}$, and 16Ser, $n$ was taken as 2 because the surface tension was measured in pure water, ${ }^{50}$ whereas for $12 \mathrm{Lys} 12$ it was taken as 1 because of the excess $0.0100 \mathrm{~mol} \mathrm{dm}^{-3} \mathrm{NaOH}$ in solution. ${ }^{51}$ The calculated interfacial parameters for the studied surfactants are shown in Table 1.

For the 12Lys12 surfactant, the $\mathrm{cmc}$ was determined in 0.010 mol dm ${ }^{-3} \mathrm{NaOH}(\mathrm{pH} 12.0 \pm 0.2)$ to prevent the precipitation of the insoluble acidic form upon high dilution. Despite the differences in temperature and ionic strength (the former has a small effect on the $\mathrm{cmc}$ ), some comments can be made. The surfactant with the lowest $\mathrm{cmc}$ is the double-chained 12Lys 12 as a result of its high hydrophobicity, and it also shows the smallest molecular area. The surfactant with the smallest surface excess is $8 \mathrm{Lys} 8$ as a result of its high solubility. This amphiphile also has the largest area per molecule, $1.1 \mathrm{~nm}^{2}$, which is smaller than that of a dicationic $\mathrm{C} 8$ gemini surfactant with a $\mathrm{C} 3$ spacer $^{52}$ (one methylene group less than in the present surfactant). All surfactants are micellizing amphiphiles in the dilute regime. In the cationic/anionic mixtures at appropriate mixing ratios, as will be shown, vesicles can be stabilized.

Figure 3 shows the phase maps of the two studied systems for the dilute region.

For the 12Lys12/12Ser system (Figure 3a) on the anionic-rich side, the samples are viscous and show the presence of clusters of a crystalline flocculate. The flocculate increases in abundance as the amount of $12 \mathrm{Ser}$ increases. For small amounts of the single-chained surfactant, almost no flocculate is seen, and the samples are essentially composed of micrometer-sized tubules,

(46) Stilbs, P. Prog. Nucl. Magn. Reson. Spectrosc. 1987, 19, 1-45.

(47) Söderman, O.; Stilbs, P. Prog. Nucl. Magn. Reson. Spectrosc. 1994, 26, $445-483$.

(48) Bellare, J. R.; Davis, H. T.; Scriven, L. E.; Talmon, Y. J. Electron Microsc. Tech. 1988, 10, 88-111.

(49) Talmon, Y. Ber. Bunsen-Ges. Phys. Chem. 1996, 3, 364-372

(50) Alami, E.; Beinert, G.; Marie, P.; Zana, R. Langmuir 1993, 9, 1465-1467.

(51) Yoshimura, T.; Sakato, A.; Tsuchiya, K.; Ohkubo, T.; Sakai, H.; Abe, M.; Esumi, K. J. Colloid Interface Sci. 2007, 308, 466-473.

(52) Wettig, S. D.; Verrall, R. E. J. Colloid Interface Sci. 2001, 235, 310-316. 


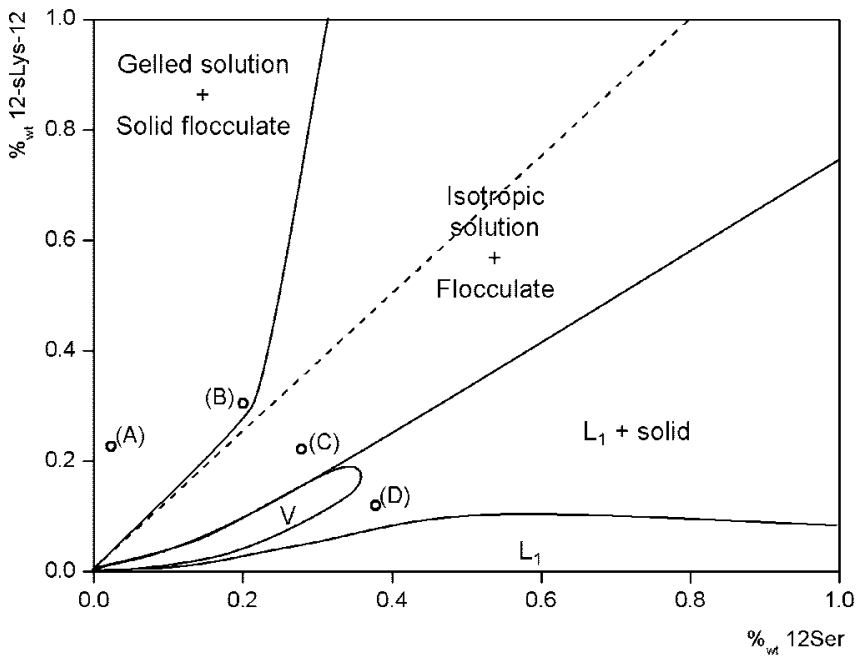

(a)

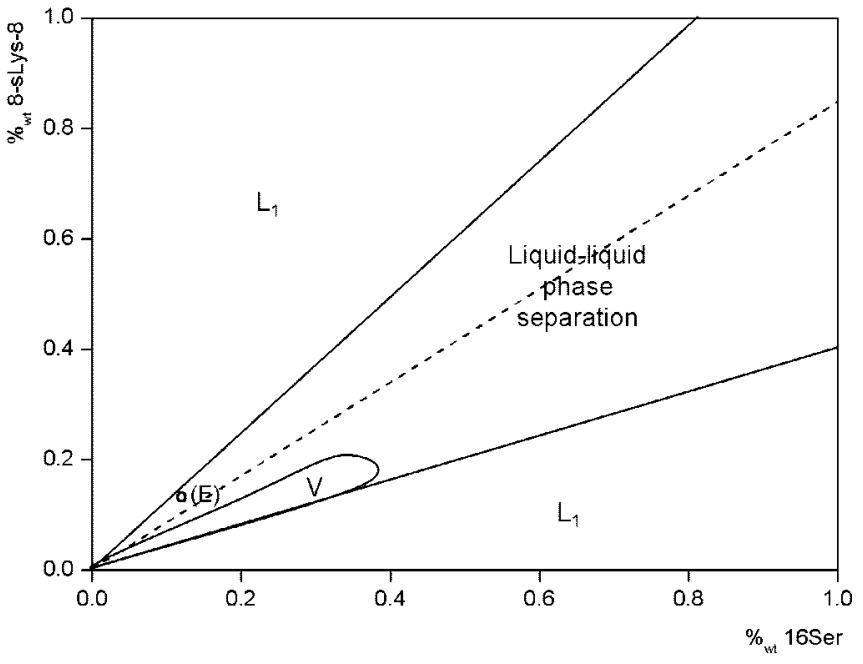

(b)

Figure 3. Phase maps for the catanionic systems: (a) $12 \mathrm{Lys} 12 / 12 \mathrm{Ser}, 25^{\mathrm{a}} \mathrm{C}$ and (b) $8 \mathrm{Lys} 8 / 16 \mathrm{Ser}, 35^{\circ} \mathrm{C}$. Legend: dashed lines, equimolar composition; $\mathrm{V}$, bluish vesicle solution; $\mathrm{L}_{1}$, clear micellar solution. Letters in parentheses refer to imaged samples in Figure 4.

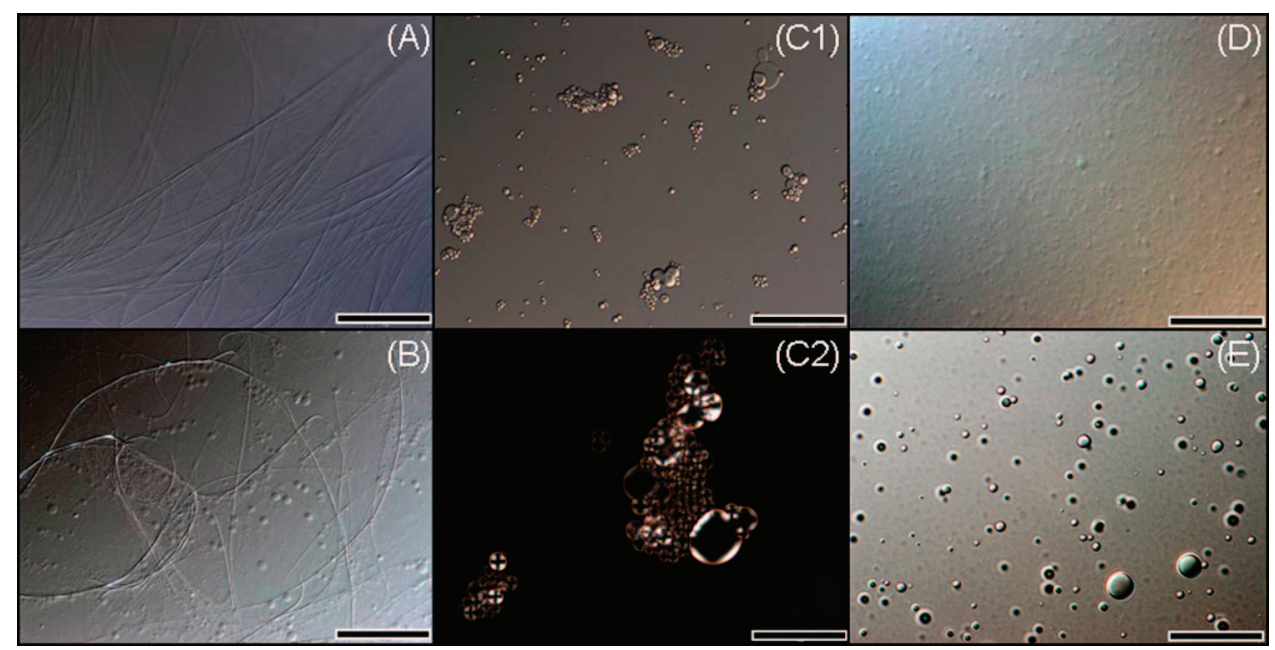

Figure 4. Light microscopy imaging of samples indicated in the phase maps of the 12Lys12/12Ser (A-D) and 8Lys8/16Ser (E) systems. The sample composition is given by the Lys/Ser wt \% ratio and molar fraction of the Ser surfactant: (A) 0.23/0.02, $X_{12 \text { Ser }}=0.10$, tubules; (B) 0.30/0.20, $X_{12 S e r}$ $=0.45$, tubules and spherical aggregates; $(\mathrm{C} 1, \mathrm{C} 2) 0.22 / 0.28, X_{12 \mathrm{Ser}}=0.61$, birefringent flocs with Maltese crosses; (D) $0.11 / 0.14, X_{12 \mathrm{Ser}}=0.61$, amorphous solid particles; (E) 0.10/0.15, $X_{16 \mathrm{Ser}}=0.45$, dispersed droplets. Scale bars: (A, C2, D) $20 \mu \mathrm{m}$; (B, C1, E) $50 \mu \mathrm{m}$.

with some showing small defects on the surface (Figure 4A). With increasing amounts of $12 \mathrm{Ser}$, the flocculate becomes more evident, and the tubules have a different morphology (Figure 4B). With increasing amounts of 12 Ser, a phase region comprising turbid dispersions of a white flocculate denser than the isotropic solution is attained. The dispersed flocculate is expected to be essentially made of 12Lys12, whereas the isotropic solution is presumably micellar in nature and rich in the single-chained surfactant. The turbid portion was imaged and was shown to be composed of collapsed multilamellar structures ${ }^{53,54}$ exhibiting birefringent Maltese crosses (Figure 4, C1 and C2).

Upon further addition of 12 Ser to the system, a new twophase region is formed, where a fine solid precipitate (Figure 4D) coexists with an isotropic solution. Because of its low viscosity, the solution should be composed of 12 Ser-rich micelles. This two-phase region separates a bluish vesicle lobe from the isotropic $\mathrm{L}_{1}$ phase. For a $0.5 \mathrm{wt} \%$ total surfactant concentration,

(53) Lipowsky, R. Curr. Opin. Struct. Biol. 1995, 5, 531-540.

(54) Khopade, A. J.; Shenoy, D. B.; Khopade, S. A.; Jain, N. K. Langmuir 2004, 20, 7368-7373. the vesicle lobe extends itself from $0.70 \leq X_{12 \text { Ser }} \leq 0.74$ and is separated from the $\mathrm{L}_{1}$ phase by the two-phase region spanning $0.74<X_{12 \text { Ser }}<0.85$. The large extent of flocculation and precipitation seen for the 12Lys12/12Ser system is highly favored by the chain length symmetry because the packing of molecules with equal length facilitates the stabilization of a crystalline lattice. $^{40}$

By comparison, the asymmetric system 8Lys8/16Ser shows a different behavior, presenting only one region where phase separation occurs. This region extends to both sides of the equimolarity line, and liquid-liquid phase separation takes place (Figure 4E). Both liquids are isotropic and show no traces of optical birefringence, easily forming turbid dispersions when samples are disturbed. On the 8Lys8-rich side, a micellar region is observed, as well as on the $16 \mathrm{Ser}$-rich side. On the cationic side, a vesicle lobe is present, contiguous with the $L_{1}$ phase.

Because the phase behavior and microstructure evolution are clearly different for the two systems, a detailed NMR diffusometry and cryo-TEM investigation was carried out for a total surfactant concentration of $0.5 \mathrm{wt} \%$. 


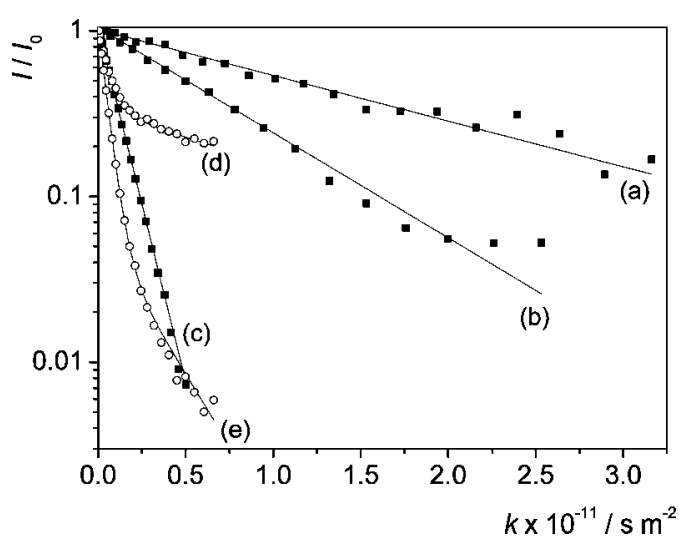

Figure 5. Echo attenuation curves for the main $\left(\mathrm{CH}_{2}\right)_{n}$ proton signals of selected samples of 8Lys8/16Ser $(a-c)$ and 12Lys12/12Ser (d, e) with total surfactant concentration of $0.5 \mathrm{wt} \%$. Sample composition: (a) $X_{16 \mathrm{Ser}}=0.60$, (b) $X_{16 \mathrm{Ser}}=0.74$, (c) $X_{16 \mathrm{Ser}}=0.94$, (d) $X_{12 \mathrm{Ser}}=0.70$, and (e) $X_{12 \mathrm{Ser}}=0.94$.

3.2. Evolution of Microstructure from NMR Diffusometry. The surfactant self-diffusion was monitored for the $\left(\mathrm{CH}_{3}\right) \mathrm{N}^{+}$ peak, belonging to the cationic Ser-based surfactants, and for the main $\left(\mathrm{CH}_{2}\right)_{n}$ peak, assigned to the alkyl chain of both cationic and anionic surfactants. We note that water diffusion was also measured; however, because there were no significant entrapment/ obstruction effects by the vesicles when compared to the micellar samples, the data was of little significance for aggregation studies.

Figure 5 shows the decays of illustrative samples for the 8Lys8/ $16 \operatorname{Ser}(\mathrm{a}-\mathrm{c})$ and 12Lys12/12Ser $(\mathrm{d}, \mathrm{e})$ systems as followed by the $\left(\mathrm{CH}_{2}\right)_{n}$ protons. For the asymmetric $8 \mathrm{Lys} 8 / 16 \mathrm{Ser}$ system, all of the observed echo decays $(\mathrm{a}-\mathrm{c})$ are single-exponential. However, the 12Lys12/12Ser system shows only biexponential decays $(\mathrm{d}, \mathrm{e})$ for the main chain peak and single-exponential decays for the $\left(\mathrm{CH}_{3}\right) \mathrm{N}^{+}$peak.

Figure 6 shows the variation of the self-diffusion coefficient with composition for the two systems. The diffusivity change with molar fraction of cationic surfactant for the 12Ly12/12Ser system (Figure 6a) follows a trend similar to that for the previously reported system 12 Lys $12 /$ DATB. ${ }^{39}$ As 12 Lys 12 is added to 12 Serrich micelles, a decrease is observed in both fast (12Ser) and slow (12Lys12) self-diffusion coefficients. Since the doublechained surfactant is much less soluble than the serine derivative, it is easily taken up by $12 \mathrm{Ser}$ micelles. This uptake originates a size increase and thus a slowdown of the aggregate diffusivity. The observed slow self-diffusion coefficient allows a reasonable estimate of micelle size (Table 2) because there is no free monomer averaging effects for 12Lys 12 , contrary to the situation for $12 \mathrm{Ser}$. Adding more double-chained surfactant to the system leads to phase separation for $0.74<X_{12 \mathrm{Ser}}<0.85$. Vesicles are formed for $0.70<X_{12 \mathrm{Ser}}<0.74$ (as confirmed by cryo-TEM), and in this region, the slow-diffusing component does not significantly change its value, remaining in the range of $(6.56-6.82) \times 10^{-11}$ $\mathrm{m}^{2} \mathrm{~s}^{-1}$. For this mixing ratio interval, the fast-diffusing component diffusion coefficient is relatively high, decreasing continuously as more $12 \mathrm{Lys} 12$ is added to the system. This implies that micelles should coexist with the mixed vesicles. Increasing the amount of 12Lys12 in the system causes the gradual disappearance of the 12 Ser micelles and the formation of more mixed vesicles, thus lowering the $12 \mathrm{Ser}$ diffusivity.

The self-diffusion coefficients plotted in Figure 6 allow the calculation of the aggregate sizes present in the two systems. The results are shown in Tables 2 and 3 and plotted in Figure 7 for easier visualization. The hydrodynamic radii were calculated using the Stokes-Einstein equation. For the calculation of the aggregate size in samples where a biexponential decay occurs (12Lys12/12Ser), the value of the slow-diffusing component corresponding to the double-chained surfactant was used. This surfactant is less soluble than the single-chained one and therefore is expected to reside only in its aggregated form, either micelles or vesicles. The use of the Stokes-Einstein equation assumes a spherical shape for the aggregates. Therefore, size calculations in the regions where significant micellar growth takes place should be viewed as merely indicative of qualitative trends.

Figure $6 \mathrm{~b}$ shows the self-diffusion coefficient values for the asymmetric system $8 \mathrm{Lys} 8 / 16 \mathrm{Ser}$. One immediate difference with respect to the 12Lys12/12Ser system is seen: only singleexponential echo decays are observed, indicating that the amount of free monomer in solution is minimal, even in the micellar region. This finding is due to synergistic effects in $\mathrm{cmc}$ reduction upon mixing oppositely charged surfactants, ${ }^{6}$ which is further enhanced by the low cmc of 16 Ser.

The self-diffusion coefficients traced by the $\left(\mathrm{CH}_{3}\right) \mathrm{N}^{+}$and the $\left(\mathrm{CH}_{2}\right)_{n}$ protons are comparable, differing slightly for $\mathrm{X}_{16 \mathrm{Ser}}=$ $0.66,0.68$, and 0.70 . These compositions are located in the transition region, where elongated micelles form. Additionally, the calculated surfactant self-diffusion coefficient of these samples is smaller than that of vesicles. Even if not initially expected, this is due to the relative size of the vesicles and that of the elongated micelles. The latter, which are larger than the vesicles and subject to entanglement effects, will experience slower translational diffusion. The self-diffusion coefficient measured from the hydrocarbon chains corresponds to both surfactants, whereas that calculated from the polar headgroups monitors only the single-chained one. A reasonable explanation for the difference between the two values could be the slightly faster monomer exchange of single-chained amphiphiles between elongated micelles in the sites where overlapping and entanglement occur.

Again, and in contrast with the 12Lys12/12Ser system, only one decay is observed in the vesicular region. It is therefore reasonably inferred that no micelles exist in this phase. The vesicular region is larger than that of the symmetric system, occurring in the range of $0.58 \leq X_{16 \mathrm{Ser}}<0.66$. Even though phase separation does not take place, a large jump in the selfdiffusion coefficient occurs around $X_{16 \mathrm{Ser}}=0.76-0.77$. It remains relatively constant within the range of $0.86 \leq X_{16 \mathrm{Ser}}<0.98$, showing just a small decrease for $X_{16 \mathrm{Ser}}<0.82$. Probably above this concentration the small 16Ser micelles are able to incorporate 8Lys8 without changing their shape significantly. Upon further increasing the amount of the double-chained surfactant, growth takes place via the elongation of the micelles.

3.3. Cryo-TEM Studies. Cryo-TEM imaging was done to explore further the morphology and size of the aggregates in solution. Figure 8 shows micrographs with the types of aggregates present in illustrative samples from the two studied systems. For the $12 \mathrm{Lys} 12 / 12 \mathrm{Ser}$ sample with $X_{12 \mathrm{Ser}}=0.70$, only single-walled spherical vesicles are observed (Figure $8 \mathrm{a}$ ). For the $8 \mathrm{Lys} 8 / 16 \mathrm{Ser}$ system, two samples are shown. The composition with $X_{16 \mathrm{Ser}}=$ 0.60 shows a majority population of single-walled vesicles, but with some large nonspherical vesicles enclosing smaller ones (lower panel of Figure 8b). For the large vesicles, the bilayer does not appear to be uniformly flexible, showing some sections with low curvature. The sample at $X_{16 \mathrm{Ser}}=0.60$ (bluish solution but apparently viscoelastic in character), where vesicles were suspected to coexist with large micelles, was also imaged. The fragility of the bilayers for this critical transition composition could make them more susceptible to damage and disruption during the blotting process. ${ }^{40,43,55}$ Also, the presumed small number of vesicles expected could make them harder to visualize. 


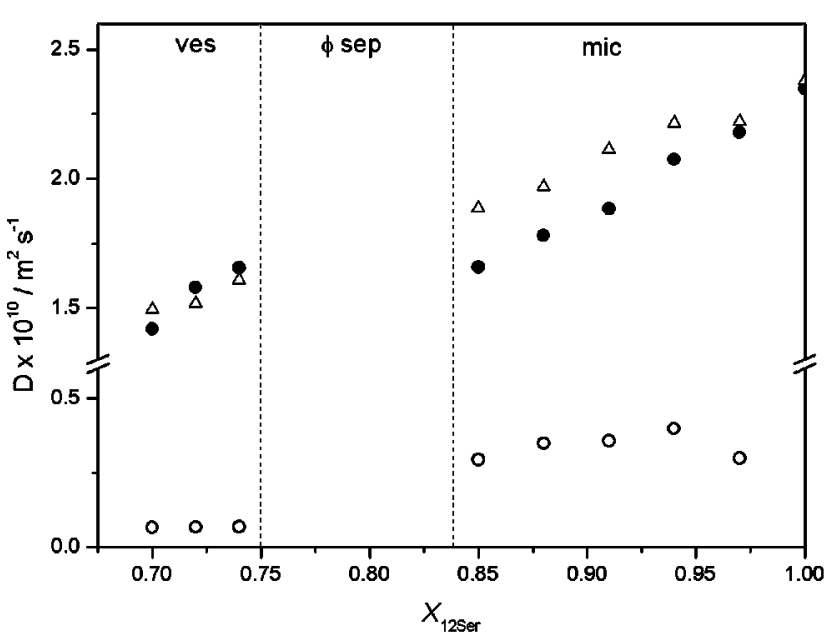

(a)

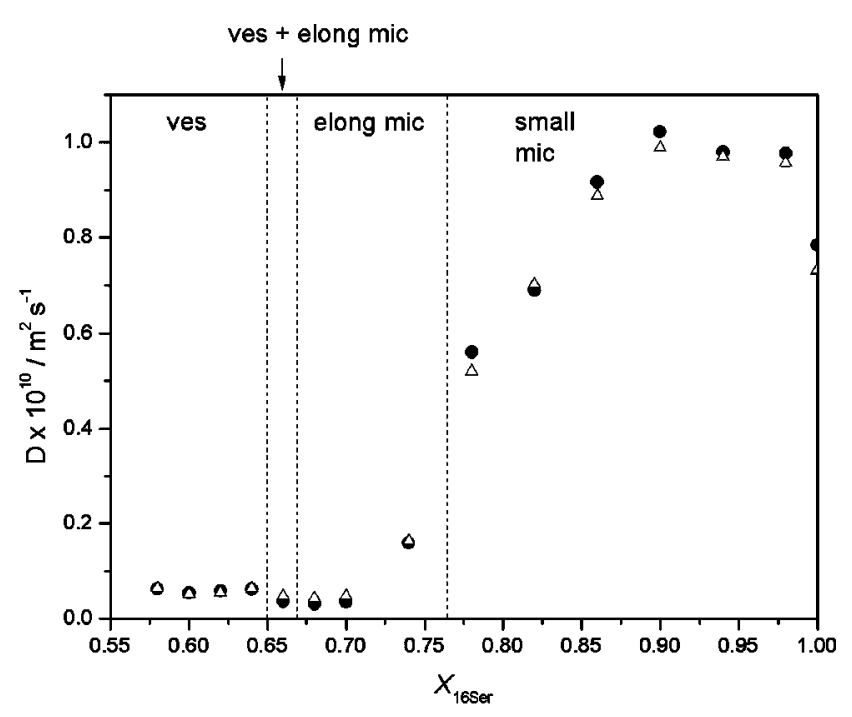

(b)

Figure 6. Self-diffusion coefficients of the surfactant for (a) 12Lys12/12Ser and (b) 8Lys 8/16Ser systems, both with 0.5 wt $\%$ total surfactant. Legend: (a) (๑) fast-diffusing component and $(\bigcirc)$ slow-diffusing component; (b) (๑) surfactant diffusivity monitored from single-exponential echo decays and $(\triangle)$ diffusivity of the single-chain surfactant (serine-derived), as traced from the $\left(\mathrm{CH}_{3}\right) \mathrm{N}^{+}$protons.

Table 2. Variation of the Self-Diffusion Coefficient and Aggregate Hydrodynamic Radius with Composition for the 12Lys12/12Ser System (0.5 wt \% Total Surfactant), $\theta=25{ }^{\circ} \mathrm{C}$

\begin{tabular}{|c|c|c|c|c|c|}
\hline $\begin{array}{l}\text { phase } \\
\text { region }\end{array}$ & $X_{12 \text { Ser }}$ & $\begin{array}{c}D_{3 \mathrm{ppm}} \times \\
10^{10}\left(\mathrm{~m}^{2} \mathrm{~s}^{-1}\right)\end{array}$ & $\begin{array}{l}D_{\text {fast, } 1.2 \mathrm{ppm}} \times \\
10^{10}\left(\mathrm{~m}^{2} \mathrm{~s}^{-1}\right)\end{array}$ & $\begin{array}{l}D_{\text {slow } 1.2 \mathrm{ppm} \times} \times \\
10^{12}\left(\mathrm{~m}^{2} \mathrm{~s}^{-1}\right)\end{array}$ & $R_{\mathrm{H}}(\mathrm{nm})^{a}$ \\
\hline \multirow{3}{*}{ ves } & 0.70 & 1.49 & 1.42 & 6.56 & 30 \\
\hline & 0.72 & 1.52 & 1.58 & 6.71 & 29 \\
\hline & 0.74 & 1.61 & 1.66 & 6.82 & 29 \\
\hline \multirow{6}{*}{ mic } & 0.85 & 1.89 & 1.66 & 29.4 & 6.6 \\
\hline & 0.88 & 1.97 & 1.78 & 34.9 & 5.6 \\
\hline & 0.91 & 2.11 & 1.88 & 35.7 & 5.5 \\
\hline & 0.94 & 2.21 & 2.07 & 39.9 & 4.9 \\
\hline & 0.97 & 2.22 & 2.18 & 29.8 & 6.6 \\
\hline & 1.00 & 2.38 & 2.35 & & 0.8 \\
\hline
\end{tabular}

Table 3. Variation of the Self-Diffusion Coefficient and Aggregate Hydrodynamic Radius with Composition for the 8Lys8/16Ser System (0.5 wt \% Total Surfactant), $\theta=35{ }^{\circ} \mathrm{C}$

\begin{tabular}{|c|c|c|c|c|c|}
\hline phase region & $X_{16 \mathrm{Ser}}$ & $\begin{array}{c}D_{3 \mathrm{ppm}} \times 10^{11} \\
\left(\mathrm{~m}^{2} \mathrm{~s}^{-1}\right)\end{array}$ & $\begin{array}{c}D_{1.2 \mathrm{ppm}} \times 10^{11} \\
\left(\mathrm{~m}^{2} \mathrm{~s}^{-1}\right)\end{array}$ & $\begin{array}{c}R_{\mathrm{H}} \\
(\mathrm{nm})^{a}\end{array}$ & $\begin{array}{c}R_{\mathrm{H}} \\
(\mathrm{nm})^{b}\end{array}$ \\
\hline \multirow{4}{*}{ ves } & 0.58 & 0.65 & 0.63 & 39 & 40 \\
\hline & 0.60 & 0.51 & 0.54 & 49 & 46 \\
\hline & 0.62 & 0.55 & 0.58 & 46 & 43 \\
\hline & 0.64 & 0.64 & 0.62 & 39 & 40 \\
\hline ves + elong mic & 0.66 & 0.48 & 0.37 & 52 & 67 \\
\hline \multirow{3}{*}{ elong mic } & 0.68 & 0.44 & 0.31 & 57 & 80 \\
\hline & 0.70 & 0.48 & 0.35 & 51 & 72 \\
\hline & 0.74 & 1.64 & 1.59 & 15 & 16 \\
\hline \multirow{7}{*}{ small mic } & 0.78 & 5.21 & 5.61 & 4.8 & 4.5 \\
\hline & 0.82 & 7.04 & 6.90 & 3.5 & 3.6 \\
\hline & 0.86 & 8.89 & 9.17 & 2.8 & 2.7 \\
\hline & 0.90 & 9.90 & 10.2 & 2.5 & 2.4 \\
\hline & 0.94 & 9.70 & 9.80 & 2.6 & 2.5 \\
\hline & 0.98 & 9.57 & 9.77 & 2.6 & 2.6 \\
\hline & 1.00 & 7.32 & 7.84 & 3.4 & 3.2 \\
\hline
\end{tabular}

Vitrified samples were thus prepared, with gentle blotting, and repeated. As can be seen, vesicles are present, in coexistence with large wormlike micelles, albeit in different grid regions of the sample. It can be seen that these vesicles are highly deformed and the bilayers show a large number of defects and irregularities (an effect that is not attributed to crowding because in other areas small vesicles are also deformed).

When performed with statistical significance, the size calculation of vesicles based on cryo-TEM imaging is an invaluable method as the obtained images consist of the direct projection of the vesicle shape and it is then possible to measure the aggregate size directly. ${ }^{56,57}$ Quantitative size assessment of the vesicles was done by the measurement of the radii of 636 vesicles for the 12Lys12/12Ser system and 768 vesicles for the $8 \mathrm{Lys} 8 / 16 \mathrm{Ser}$ system. The size distribution and fitting are plotted in Figure 9. A small skewing of the radii distribution toward larger sizes is observed, and a log-normal fitting of the data can be done, according to the expression

$$
P(R)=\frac{1}{\sqrt{2 \pi} w R} \mathrm{e}^{-\left[\ln \left(R / R_{\mathrm{m}}\right)\right]^{2} / 2 w^{2}}
$$

where $R_{\mathrm{m}}$ stands for the median vesicle radius and $w$ is the width of the log-normal distribution. The mean value for the vesicle radius, $\langle R\rangle$, is given by

$$
\langle R\rangle=R_{\mathrm{m}} \mathrm{e}^{w^{2} / 2}
$$

The value of $38.7 \mathrm{~nm}$ was obtained for the sample with $X_{12 \mathrm{Ser}}$ $=0.70$ and $44.8 \mathrm{~nm}$ for the sample with $X_{16 \mathrm{Ser}}=0.60$. These values are in good agreement with the sizes calculated by NMR (Tables 2 and 3).

\section{Discussion}

4.1. Micelle-Vesicle Transition: Chain Length Symmetry Effects. The shape and size evolution of the mixed aggregates in the two systems can be discussed comparatively and also in light of previously reported symmetric/asymmetric catanionic systems.

(55) Vinson, P. K.; Talmon, Y.; Walter, A. Biophys. J. 1989, 56, 669-681. (56) Coldren, B.; Zanten, R. v.; Mackel, M. J.; Zasadzinski, J. A. Langmuir 2003, 19, 5632-5639.

(57) Egelhaff, S. U.; Wehrli, E.; Müller, M.; Adrian, M.; Schurtenberger, P. J. Microsc. 1996, 184, 214-228.

(58) Leng, J.; Egelhaaf, S. U.; Cates, M. E. Biophys. J. 2003, 85, 1624-1646. (59) Helfrich, W. Z. Naturforsch. 1973, 28, 693-703. 


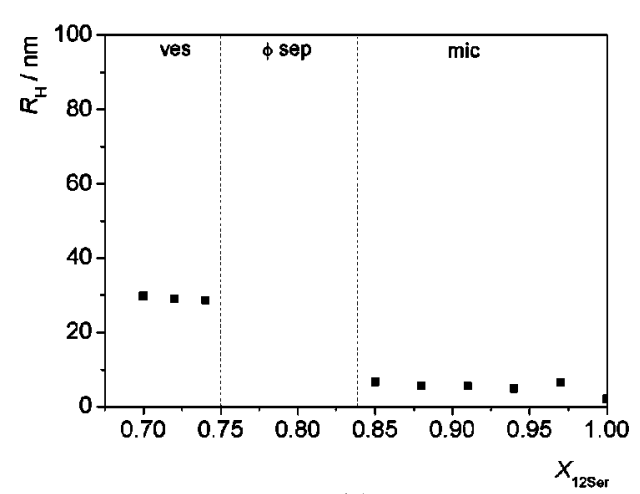

(a)

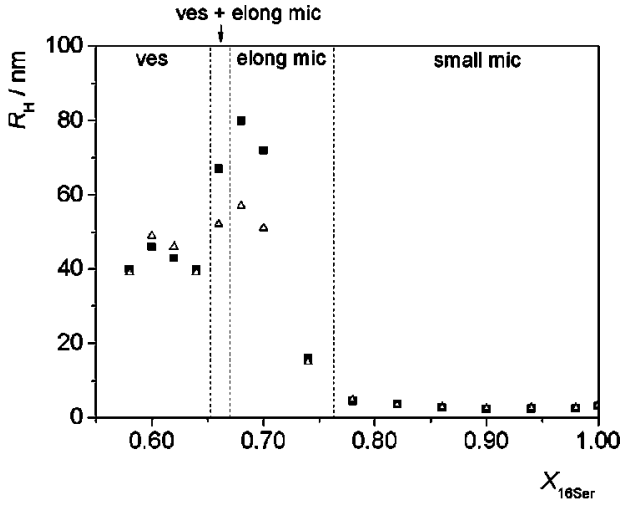

(b)

Figure 7. Aggregate hydrodynamic radius as a function of the molar fraction of Ser-based surfactant in the mixture for (a) the 12Lys12/12Ser system and (b) the 8 Lys $8 / 16$ Ser system. There is a constant $0.5 \mathrm{wt} \%$ total surfactant for both systems. (ם) Size calculated from $D_{1.2} \mathrm{ppm}$ and $(\triangle$, panel b) size calculated from $D_{3}$ ppm.

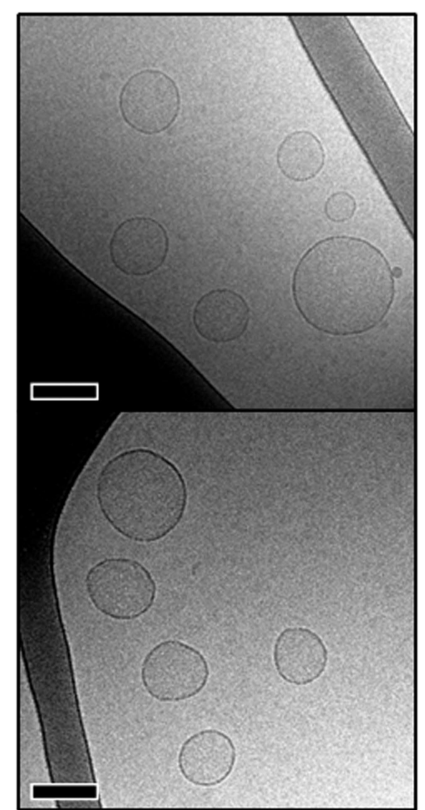

(a)

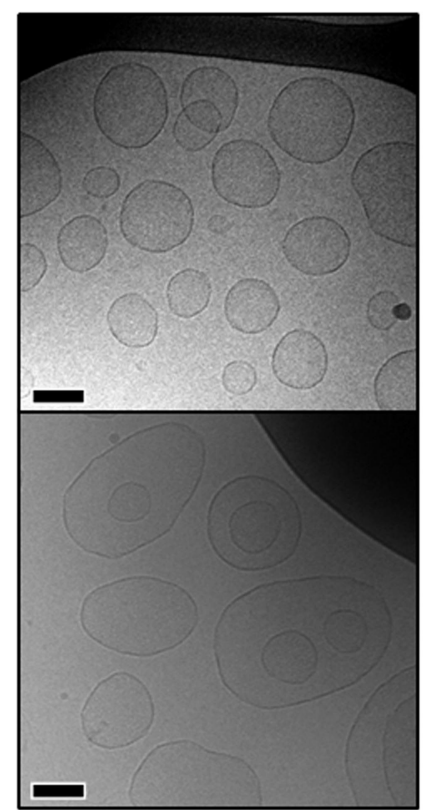

(b)

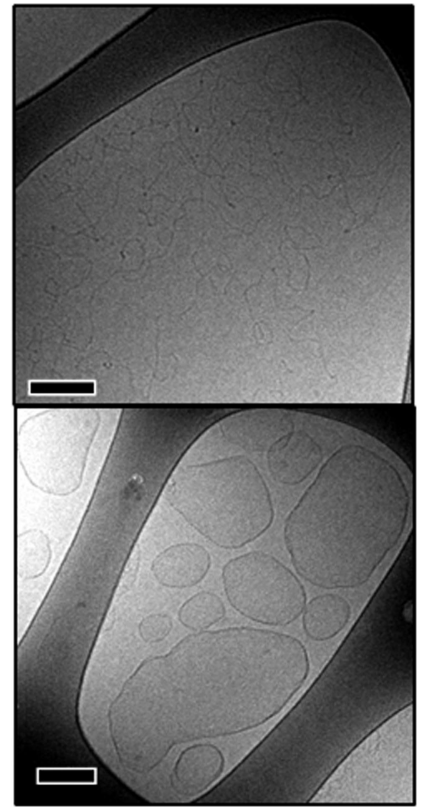

(c)

Figure 8. Representative cryo-TEM micrographs of (a) $12 \mathrm{Lys} 12 / 12 \mathrm{Ser}$ (at $25^{\circ} \mathrm{C}$ ) and (b, c) $8 \mathrm{Lys} 8 / 16 \mathrm{Ser}$ (at $35^{\circ} \mathrm{C}$ ). All samples have 0.5 wt $\%$ total surfactant. Description: (a) $X_{12 \mathrm{Ser}}=0.70$, small unilamellar vesicles; (b) $X_{16 \mathrm{Ser}}=0.60$, small unilamellar vesicles and larger vesicles enclosing small ones; (c) $X_{16 \mathrm{Ser}}=0.66$, coexisting wormlike micelles (top) with large deformed vesicles (bottom). Scale bars: $100 \mathrm{~nm}$.

Within the micellar region of the symmetric system 12Lys12/ $12 \mathrm{Ser}$, weak micellar growth is seen to occur (average apparent radius of $5.8 \mathrm{~nm}$ in the range of $0.85 \leq X_{12 \mathrm{Ser}}<1$ ). We recall that the micellar size was calculated from the self-diffusion coefficient of 12Lys 12, which resides solely in the mixed micelles (negligible free monomer contribution to diffusion averaging). As can be seen from Figure $6 \mathrm{a}$, the 12 Ser self-diffusion coefficient gradually decreases as 12Lys12 is added to the system, whereas the diffusion of the micelles remains constant at an average value of $3.39 \times 10^{-11} \mathrm{~m}^{2} \mathrm{~s}^{-1}$. Such behavior is possible only if growth does not occur significantly but rather the micelle number is increasing, with concomitant removal of 12 Ser monomer from solution. In the vesicle region, when decreasing the amount of 12 Ser from $X_{12 \text { Ser }}=0.74$ to 0.70 , a limited size increase is observed from 28.6 to $29.8 \mathrm{~nm}$ (Figure $7 \mathrm{a}$ ).

This limited micellar growth and micelle/vesicle coexistence region, observed upon addition of the oppositely charged surfactant, is similar to that observed for other symmetric chain systems. For the 12Lys12/ dodecyltrimethylammonium bromide
(DTAB) system, an intermediate phase separation (with solid formation) is also observed, in striking similarity to that for 12Lys12/12Ser. For the DTAB/sodium dodecylbenzenesulphonate (SDBS) and dodecyltrimethylammonium chloride (DTAC)/ sodium dodecylbenzenesulphonate (SDBS) mixtures, ${ }^{41}$ where SDBS is a branched dodecyl surfactant, the micelle-vesicle transition is continuous, with small micelles always present. In sodium dodecylsulphate (SDS)/didodecyldimethylammonium bromide (DDAB) on the anionic-rich side, depending on the total surfactant concentration, the vesicle-micelle transition is either continuous $(<0.5 \mathrm{wt} \%)$, again involving small micelles and vesicles, or discontinuous ( $>0.5 \mathrm{wt} \%$ ), with phase separation (solid phase). ${ }^{3}$ The only exception to these common trends in symmetric systems appears to be the SDS/DTAB mixture. ${ }^{40}$ The transition region is a two-phase region where a lamellar phase is segregated from a $\mathrm{L}_{1}$ phase with elongated micelles, and this phase separation is kinetically very slow. ${ }^{40}$

For the case of the 8Lys8/16Ser system, the asymmetry in chain length renders a distinct behavior, though a continuous 


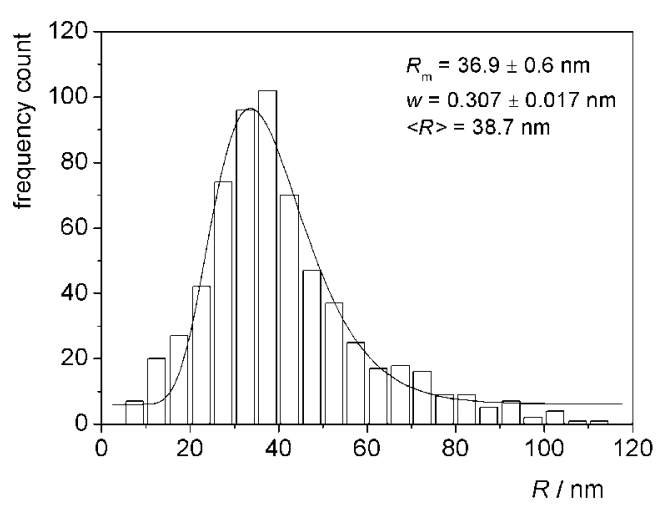

(a)

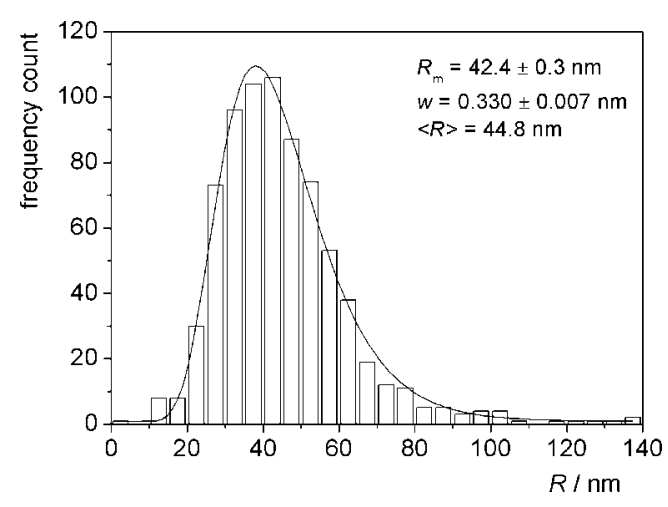

(b)

Figure 9. Size distribution obtained from cryo-TEM micrographs for (a) $12 \mathrm{Lys} 12 / 12 \mathrm{Ser}$ vesicles, $X_{12 \mathrm{Ser}}=0.70$ and (b) $8 \mathrm{Lys} 8 / 16 \mathrm{Ser}$ vesicles, $X_{16 \mathrm{Ser}}$ $=0.60$. The solid line represents the log-normal fitting of the size distribution with the obtained median radius $\left(R_{\mathrm{m}}\right)$, width $(w)$, and mean radius $\langle R\rangle$.

transition is also observed. The micellar growth is not significant for the mixing ratios of $0.86 \leq X_{16 \mathrm{Ser}} \leq 1$, lying in the range of $2.4-3.2 \mathrm{~nm}$. Upon adding more $8 \mathrm{Lys} 8$ surfactant to the system, micelles increase in size to 3.6 and $4.5 \mathrm{~nm}\left(X_{16 \mathrm{Ser}}=0.82\right.$ and 0.78 , respectively). For even higher concentration of $8 \mathrm{Lys} 8$, the solutions remain clear but display viscous behavior (possibly viscoelastic), with the apparent micellar sizes showing a dramatic increase. This indicates the formation of elongated micelles, as also observed by cryo-TEM. A large jump in the growth is observed between $X_{16 \mathrm{Ser}}=0.74$ and 0.70 (from 16 to $80 \mathrm{~nm}$ ). The sample with composition $X_{16 \text { Ser }}=0.66$ is bluish, and the coexistence of vesicles and elongated micelles was observed. The vesicles formed in the range of $0.58 \leq X_{16 \mathrm{Ser}} \leq 0.64$ do not vary significantly in size with varying bulk composition of the system and have an average radius of $40.2 \mathrm{~nm}$. No micelles are detected in this region. Phase separation does not occur; instead, vesicles are separated from the elongated micellar region by a small coexistence range (around $X_{16 \mathrm{Ser}}=0.66$ ), where the samples are both bluish and viscous. Because of the system composition, the vesicles are likely to have defects and perforations in the membrane as well as fragmentation. ${ }^{2,40,42}$ The behavior for this system is also remarkably similar to that of the cetyltrimethylammonium bromide (CTAB)/sodium octylsulphate (SOS) asymmetric system, ${ }^{43}$ namely, for the SOS-rich vesicles, in which an abrupt increase in the micelle size occurs immediately before vesicle formation. Additionally, for borderline compositions of the vesicle-micelle boundary, viscoelastic behavior and an increase in turbidity are also observed, indicating that vesicles coexist with elongated micelles. ${ }^{43}$

The aggregate evolution in the symmetric/asymmetric mixture system can be reasonably accounted for in terms of the surfactant critical packing parameter (CPP) model and the effect of chain symmetry on the preferred aggregate curvature. We will illustrate this with the 12Lys12/12Ser and 8Lys8/12Ser systems. As previously stated, chain symmetry is responsible for the larger radii observed for the 12Lys12/12Ser micelles as compared to 8 Lys $8 / 16$ Ser once (Tables 2 and 3). Because of the similarity in chain length, the association between 12 sLys 12 and 12 Ser renders an effective pseudotriple chained "pair." This pair should have a higher CPP than that of the double-chained surfactant (and naturally of the single-chained one), owing to the electrostatic attractions between charged headgroups. It is then reasonable to assume that, under these conditions, small micelles (spheroidal or not) should be formed only under conditions of a high excess of $12 \mathrm{Ser}$, where the small packing parameter of the micellizing surfactant predominates. ${ }^{42}$ The micelles formed before phase separation likely show a deviation from spherical shape, possibly consisting of prolates or disk-like assemblies (disks or oblates). ${ }^{58}$ Furthermore, the occurrence of phase separation for this system should imply that large aggregates, as in the case of elongated micelles, are not stable owing to curvature effects and to the mean CPP value of the "catanionic pairs."

The fact that the 12Lys12/12Ser small micelles are larger than the corresponding small micelles for 8Lys8/16Ser mixtures seems to indicate that larger curvature values are not accessible for the former system (consistent with our previous interpretations). Micelles should not increase much in size but rather deform from the spherical and cylindrical shapes, which would require larger curvature values. The impossibility of evolving to highercurvature aggregates and the fact that the ideal mixing ratio for vesicle formation is not yet achieved result in the phase separation of the amphiphiles into a collapsed lamellar phase or a solid phase and a $\mathrm{L}_{1}$ phase.

This behavior is also typical of other symmetric systems where bilayer solubilization was studied. ${ }^{42}$ The proximity in chain length between the bilayer-forming and the micellizing surfactant leads to the formation of collapsed and perforated bilayers. By contrast, in mixtures of surfactants with very different chain lengths, there is significant micellar growth. ${ }^{42}$

4.2. Vesicle Stability: Possible Mechanisms Involved. The free energy per unit area of a bilayer is the sum of the bending or energy of curvature per unit area, ${ }^{59} u_{\mathrm{b}}$, and the entropy of mixing of the amphiphiles, ${ }^{60} s$ :

$$
f_{\mathrm{b}}=u_{\mathrm{b}}-T s
$$

The main contribution to the free energy of the aggregates arises from the energy of curvature and is particularly relevant when strong interactions between the amphiphiles take place. The entropic term reflects the tendency of the individual amphiphile molecules to mix within the bilayer. The energy of curvature of the bilayer can be defined as

$$
u_{\mathrm{b}}=\frac{1}{2} k\left(c_{1}+c_{2}-c_{0}\right)^{2}+\bar{k} c_{1} c_{2}
$$

where $k$ is the mean bending modulus, $\bar{k}$ is the Gaussian (saddlesplay) modulus, $c_{0}$ is the spontaneous curvature, and $c_{1}$ and $c_{2}$ are the principal curvatures of the bilayer at a given point (inverse radii of curvature).

The $c_{0}$ parameter is strongly dependent on the composition of the system, and values different from zero can be expected if an asymmetric distribution of the amphiphiles occurs in the bilayer

(60) Andelman, D.; Kozlov, M. M.; Helfrich, W. Europhys. Lett. 1994, 25, 231-236. 
in mixed systems. ${ }^{12,61}$ Furthermore, a reduction in $k$ is also observed for mixed systems where a micellizing surfactant is present, owing to its facilitated lateral diffusion. ${ }^{53}$ The reduction of the $k$ value should then favor shape fluctuations and topology changes of the bilayer. ${ }^{62}$

For the case of the 12Lys12/12Ser mixture, vesicles are seen to coexist throughout with small micelles, whereas for the 8Lys8/ 16 Ser system, only vesicles are seen in the vesicular region. For both systems, no significant vesicle size variation is observed. NMR and cryo-TEM both show that the vesicle populations are not very polydisperse. For the symmetric system, the coexistence of two types of aggregates shows that a specific composition is adopted by the vesicles in order to maintain a favorable curvature value (resulting in a small size variation of the vesicles). The 12Ser surfactant is segregated from the bilayers to the bulk, aggregating in micelles. This is thought to occur because of the inability of this mixed system to form aggregates with curvature values between those of the largest micelle $\left(6.6 \mathrm{~nm}\right.$ for $X_{12 \mathrm{Ser}}=$ $0.85)$ and the smallest vesicle $\left(28.6 \mathrm{~nm}\right.$ for $\left.X_{12 \mathrm{Ser}}=0.74\right)$. With an increasing amount of 12Lys 12 in the system and the attainment of a specific critical composition, it is likely that the bilayers acquire an optimal spontaneous curvature, overcoming the entropy penalty for the segregation of the single surfactant to the bulk. This critical composition could also be responsible for the fact that the 12Lys12/12Ser vesicular region is smaller than that of the 8 Lys8/16Ser system.

For the 8Lys8/16Ser system, the asymmetry in chain length of the two surfactants provides added flexibility to both monolayers and bilayers, allowing a continuous transition from vesicles to micelles. The increased flexibility (reduction in $k$ ) due to the hydrophobic chain length mismatch of the amphiphiles ${ }^{11,63}$ and the further possibility of composition asymmetry of the bilayer allow a larger range of mixing ratios where the vesicles are stable. More importantly, for the asymmetric system the decrease in the bilayer bending rigidity stems from the increase in conformational entropy of the hydrophobic chains when a mismatch of lengths is observed. This difference allows the bending of the bilayer to occur with less tension, extending the vesicle stability region to a wider range of mixing ratios. The cryo-TEM log-normal distribution shows a slightly larger width than does the symmetric system. Also visible in Figure $9 \mathrm{~b}$ is the larger number of vesicles with radii close to the median, as

(61) Safran, S. A.; Pincus, P.; Andelman, A.; Makintosh, F. C. Phys. Rev. A 1991, 43, 1071-1078.

(62) Gozdz, W. T.; Gompper, G. Colloids Surf., A 2002, 208, 241-251.

(63) Szleifer, I.; Kramer, D.; Ben-Shaul, A.; Gelbart, W. M.; Safran, S. A. J. Chem. Phys. 1990, 92, 6800-6817. compared to the 12Lys12/12Ser vesicles. To cope with the change in bulk composition and the maintenance of a stable bilayer curvature, it is plausible that an increase in vesicle number (as opposite to an increase in size) and polydispersity, as effectively seen by cryo-TEM, takes place.

\section{Conclusions}

We have shown that catanionic vesicles are spontaneously formed in the two mixtures from the lysine- and serine-derived surfactants. Furthermore, the vesicle-micelle transition induced by the variation of the surfactant mixing ratio has been studied. The 12Lys12/12Ser system shows phase separation between the micellar and vesicle solutions. This is interpreted as being caused by the symmetry in chain length that prevents the formation of aggregates with curvatures intermediate between those of vesicles and small micelles. Furthermore, for this system, the vesicle composition is different from the bulk composition. In the vesicle region, small micelles are seen to coexist with the vesicles. This is a footprint of the existence of a most favorable curvature value for a specific vesicle composition, at the cost of excluding the single-chained surfactant from the bilayer.

By contrast, the 8 Lys8/16Ser system shows a continuous transition process. Elongated micelles are seen to form between small micelles and vesicles, owing to the possibility that the asymmetric system adopts a wider range of curvature values as a result of chain mismatch. The chain asymmetry delivers more flexible monolayers and bilayers, with minimized curvature stress. The composition of the vesicles is that of the bulk.

The vesicles are formed for defined mixing ratios in the ranges $0.70 \leq X_{12 \text { Ser }} \leq 0.74$ and $0.58 \leq X_{16 \text { Ser }} \leq 0.64$ for the 12 Lys $12 /$ 12 Ser and 8Lys8/16Ser systems, respectively. Cryo-TEM shows that the vesicle population is not very polydisperse and the radii values are in fairly good agreement with those measured by diffusion NMR.

The properties of these aggregates, together with the decrease in toxicity when compared to the more conventional surfactant systems, make them suitable candidates for in vivo applications and potential use in drug delivery and gene therapy.

Acknowledgment. E.F.M. kindly acknowledges the Portuguese Science Foundation (FCT) and FEDER for financial support through research project POCTI/QUI/44296/2002. We are also grateful to CIQ(UP) L1 and L5 for financial support and to FCT for Ph.D. grant SFRH/BD/16380/2004. We are thankful to Anna Carnerup for the cryo-TEM imaging. O.S. thanks the Swedish Research Council for financial support.

LA $801518 \mathrm{H}$ 